\title{
In the Right Place at the Right Time: Regulation of Cell Metabolism by IP3R-Mediated Inter-Organelle $\mathbf{C a}^{2+}$ Fluxes
}

\begin{abstract}
Ulises Ahumada-Castro' ${ }^{*}$, Galdo Bustos ${ }^{1}$, Eduardo Silva-Pavez', Andrea Puebla-Huerta ${ }^{1}$, Alenka Lovy ${ }^{1,2}$ and César Cárdenas ${ }^{1,3,4 *}$

${ }^{1}$ Geroscience Center for Brain Health and Metabolism, Center for Integrative Biology, Faculty of Sciences, Universidad Mayor, Santiago, Chile, ${ }^{2}$ Department of Neuroscience, Center for Neuroscience Research, Tufts University School of Medicine, Boston, MA, United States, ${ }^{3}$ Buck Institute for Research on Aging, Novato, CA, United States, ${ }^{4}$ Department of Chemistry and Biochemistry, University of California, Santa Barbara, Santa Barbara, CA, United States
\end{abstract}

OPEN ACCESS

Edited by:

Saverio Marchi

Marche Polytechnic University, Italy

Reviewed by:

Riccardo Filadi,

Institute of Neuroscience, National

Research Council (CNR), Italy

Giovanni Monaco,

CISTIM, Belgium

*Correspondence:

Ulises Ahumada-Castro

ulises.ahumada@mayor.cl;

uj.ahumada@gmail.com

César Cárdenas

julio.cardenas@umayor.cl

Specialty section:

This article was submitted to

Signaling,

a section of the journal

Frontiers in Cell and Developmental

Biology

Received: 15 November 2020

Accepted: 19 January 2021

Published: 02 March 2021

Citation:

Ahumada-Castro U, Bustos G Silva-Pavez E, Puebla-Huerta A, Lovy A and Cárdenas C (2021) In the Right Place at the Right Time: Regulation of Cell Metabolism by IP3R-Mediated Inter-Organelle $\mathrm{Ca}^{2+}$

Fluxes.

Front. Cell Dev. Biol. 9:629522. doi: 10.3389/fcell.2021.629522
In the last few years, metabolism has been shown to be controlled by crossorganelle communication. The relationship between the endoplasmic reticulum and mitochondria/lysosomes is the most studied; here, inositol 1,4,5-triphosphate (IP3) receptor (IP3R)-mediated calcium $\left(\mathrm{Ca}^{2+}\right)$ release plays a central role. Recent evidence suggests that IP3R isoforms participate in synthesis and degradation pathways. This minireview will summarize the current findings in this area, emphasizing the critical role of $\mathrm{Ca}^{2+}$ communication on organelle function as well as catabolism and anabolism, particularly in cancer.

Keywords: IP3Rs, calcium, endoplasmic reticulum, mitochondria, lysosome, metabolism, inositol triphosphate (IP3) receptors

\section{INTRODUCTION}

The life of a cell appears as an entanglement of complex networks of synthesis and degradation of molecules in a dynamic equilibrium essential for its viability (Muchowska et al., 2020). Within the cell, metabolic networks are completely intertwined, leading to the generation of special domains. Such domains contain a dynamic equilibrium of networks maintained by a series of regulators, particularly ions, such as calcium $\left(\mathrm{Ca}^{2+}\right)$ (Bygrave, 1967).

Calcium is a regulator and cofactor of several fundamental cellular processes, including gene transcription, secretion, apoptosis, cell proliferation and differentiation, membrane excitability, motility, fertilization, autophagy, and metabolism (Berridge et al., 2000; Clapham, 2007). Inside the cell, $\mathrm{Ca}^{2+}$ is stored in several organelles, such as the endoplasmic reticulum (ER), mitochondria, nuclear envelope, Golgi apparatus, and lysosomes (Cárdenas et al., 2010a; La Rovere et al., 2016). The complex temporal and spatial control of $\mathrm{Ca}^{2+}$ communication between these organelles is achieved by several ion transporters and channels located in the membranes of these internal stores (Bootman and Bultynck, 2020). The main $\mathrm{Ca}^{2+}$ store of the cell is the ER (Berridge et al., 2003), which releases $\mathrm{Ca}^{2+}$ to the cytoplasm and other organelles, through ryanodine receptors (RyRs) (Lanner et al., 2010) and inositol 1,4,5-triphosphate (IP3) receptors (IP3Rs) (Mikoshiba, 2015). The RyRs display a rather limited tissue distribution, mainly in excitable cells such as neurons and myocytes (Shkryl, 2017), while IP3Rs are the most ubiquitous intracellular $\mathrm{Ca}^{2+}$ channels (Parys and De Smedt, 2012; Mak and Foskett, 2015). 
Within organelles, $\mathrm{Ca}^{2+}$ plays additional roles regulating different aspects of organelle function, including metabolism. The regulatory role of $\mathrm{Ca}^{2+}$ on metabolic networks is supported by physical interactions between organelles that allow ion and molecule fluxes (Scorrano et al., 2019). These physical interactions have been defined as "membrane contact sites" (MCSs), which are highly dynamic interaction zones between two or more organelles characterized by close proximity between their membranes $(10-80 \mathrm{~nm})$, possessing specific functions and having a well-defined proteome and lipidome (Scorrano et al., 2019). So far, MCSs have been reported to be structural platforms for $\mathrm{Ca}^{2+}$ fluxes and to actively participate in intracellular signaling associated with autophagy, lipid metabolism, membrane dynamics, cellular stress response, organelle trafficking, and organelle biogenesis (Prinz et al., 2020).

Despite the above, knowledge about the regulation of metabolism by $\mathrm{Ca}^{2+}$ is still unknown in many aspects. The information about IP3R-mediated $\mathrm{Ca}^{2+}$ release in MCS and its possible implication is scarce. Thus, the role of IP3R in the MCS and how it may impact metabolism through mitochondria and lysosomes, along with its possible impact on cancer, will be reviewed.

\section{IP3R: STRUCTURE, ISOFORMS, AND FUNCTIONS}

Inositol 1,4,5-triphosphate (IP3) receptor is a family of three ligand-gated channels: type 1 IP3R (IP3R1), type 2 IP3R (IP3R2), and type 3 IP3R (IP3R3) (Prole and Taylor, 2019), each about $300 \mathrm{kDa}$ and encoded by separate genes with around 70\% homology in their amino acid sequences (Mikoshiba, 2007). The isoforms have the property of assembling into homo- or heterotetramers to form functional channels (Monkawa et al., 1995). They localize to the ER, Golgi (Bootman and Bultynck, 2020), nuclear envelope, and nucleoplasmic reticulum (Cárdenas et al., 2010a). The structure of the IP3R monomer can be divided into three functionally different domains (Boehning et al., 2001), among which there are two domains of high homology between the isoforms: the N-terminal domain with the ligand-binding pocket, including a suppressor region in addition to the IP3binding core, and the C-terminal domain containing a pore region of six transmembrane helices forming the $\mathrm{Ca}^{2+}$ channel (Mikoshiba, 2007; Serysheva, 2014). The suppressor domain reduces the affinity of the IP3R for IP3 (Iwai et al., 2007); nevertheless, it is necessary for channel opening in response to its ligand (Uchida et al., 2003). The central cytosolic regulatory domain exhibits more sequence variability between subtypes and contains interaction sites for many intracellular regulators and interacting proteins (Patterson et al., 2004). The gatekeeper domain (residues 2590-2749 of IP3R1), also called the C-terminal coupling domain, is fundamental for the activity of the channel, as mutations in the domain or its interaction with antibodies results in a non-functional $\mathrm{Ca}^{2+}$ channel (Nakade et al., 1991; Uchida et al., 2003). This domain also serves as a binding place for several regulatory proteins (Foskett et al., 2007).
Inositol 1,4,5-triphosphate is produced by hydrolysis of phosphatidylinositol 4,5-bisphosphate (PIP2) in the cell membrane through phospholipase $\mathrm{C}$ (PLC) in response to extracellular stimuli such as hormones, growth factors, and neurotransmitters that bind to G-protein-coupled receptors (Cattaneo et al., 2014), as well as to receptor tyrosine kinases (Nakamura and Fukami, 2017). Every subunit of IP3R must be bound to IP3 to trigger the opening of the channel (Alzayady et al., 2016).

The regulators associated to $\mathrm{Ca}^{2+}$ release mediated by IP3R include free $\mathrm{Ca}^{2+}$ concentration in the cytosol (mentioned here as cytoplasmic $\mathrm{Ca}^{2+}$ ), as well as in the ER (mentioned here as reticular $\mathrm{Ca}^{2+}$ ), ATP, thiol modification, and phosphorylation by protein kinases (Boehning et al., 2001; Parys and De Smedt, 2012). Additionally, many different proteins can interact with the IP3R affecting its function (Patterson et al., 2004) like the anti-apoptotic B-cell lymphoma-2 (BCL-2) (Chen et al., 2004), BCL-XL (White et al., 2005), the myeloid cell leukemia 1 (MCL-1) (Eckenrode et al., 2010), the pro-autophagic Beclin 1 (Vicencio et al., 2009), $\mathrm{Ca}^{2+}$-dependent phospholipidbinding protein Annexin A1 (ANXA1) (Vais et al., 2020), IRBIT (Bonneau et al., 2016), and the ER stress sensor IRE1 $\alpha$ (Carreras-Sureda et al., 2019).

Despite IP3R isoforms sharing a high level of sequence homology, they exhibit different properties. For example, they differ in affinity for IP3, which was established as IP3R2 > IP3R1 > IP3R3 (Prole and Taylor, 2019). Their differential modulation by cytosolic $\mathrm{Ca}^{2+}$ (Tu et al., 2005), ATP (Wagner and Yule, 2012), binding proteins (Higo et al., 2005), and post-translational modifications (Szado et al., 2008) shapes IP3R behavior in a subtype-specific manner. Additional complexity to IP3R-mediated $\mathrm{Ca}^{2+}$ signaling arises from splice variants (Nakagawa et al., 1991) and the fact that most cell types express two or three different isoforms (Wojcikiewicz, 1995) that may assemble into heterotetramers (Monkawa et al., 1995; Chandrasekhar et al., 2016).

The different isoforms show tissue- and cell-specific expression patterns, with one isoform often being predominantly expressed (Vermassen et al., 2004). For example, IP3R1 has a broad tissue distribution but is especially abundant in the cerebellum (and most of the central nervous system), where it was initially purified and characterized (Furuichi et al., 1993). It is also expressed in vascular smooth muscle cells, thyroid, uterus, and lymphocytes (DeSouza et al., 2007; Narayanan et al., 2012). IP3R2 is expressed in cardiac muscle, as well as liver, kidney, and other epithelial tissues (Klar et al., 2014), while IP3R3 is expressed in endothelial cells, testis, endocrine and exocrine pancreas, spleen, gastrointestinal tract, and thymus (De Smedt et al., 1997).

\section{IP3R AT THE ER-MITOCHONDRIA MCS AND CELLULAR METABOLISM}

The most characterized MCSs so far are the mitochondriaER contact sites (MERCs) (Wu et al., 2018), which regulate many biological processes such as apoptosis, lipid synthesis, and 
early steps of autophagy, and several aspects of mitochondrial physiology, fusion-fission dynamics, biogenesis, and degradation (Gordaliza-Alaguero et al., 2019). The IP3R has been described as the most prevalent $\mathrm{ER} \mathrm{Ca}^{2+}$ channel in MERCs. In those sites, the IP3R interacts with mitochondria through the voltage-dependent anion channels (VDACs) (Csordás et al., 2018). Additionally, it interacts with several adaptors such as the transglutaminase 2 (TG2) (D’Eletto et al., 2018), TOM70 (Filadi et al., 2018), and the glucose-regulated protein (Grp75) (Szabadkai et al., 2006; Honrath et al., 2017; Figure 1A). Finally, $\mathrm{Ca}^{2+}$ reaches the mitochondrial matrix through the channel mitochondrial calcium uniporter complex (MCUC), which interacts with many regulator proteins that affect its permeability to $\mathrm{Ca}^{2+}$
(De Stefani et al., 2016). The $\mathrm{Ca}^{2+}$ flux sustained by MERCs regulates mitochondrial metabolism and affects the activities of pyruvate dehydrogenase (PDH), isocitrate dehydrogenase (IDH), oxoglutarate dehydrogenase $(\mathrm{OGDH})$, and electron transport chain (ETC) complexes III and V (Denton, 2009; Glancy and Balaban, 2012). If the ER-mitochondria $\mathrm{Ca}^{2+}$ flux is interrupted, p-AMPK levels increase, which, in turn, increases the activity of autophagy in a mTOR-independent manner (Cárdenas et al., 2010b, 2017). SIRT1 is also increased, which participates in the activation of autophagy (Cardenas et al., 2020; Figure 1A), and triggers mitochondrial fragmentation (Lovy et al., 2020). Autophagy is a process associated with degradative pathways of macromolecules, which generates monomeric metabolites

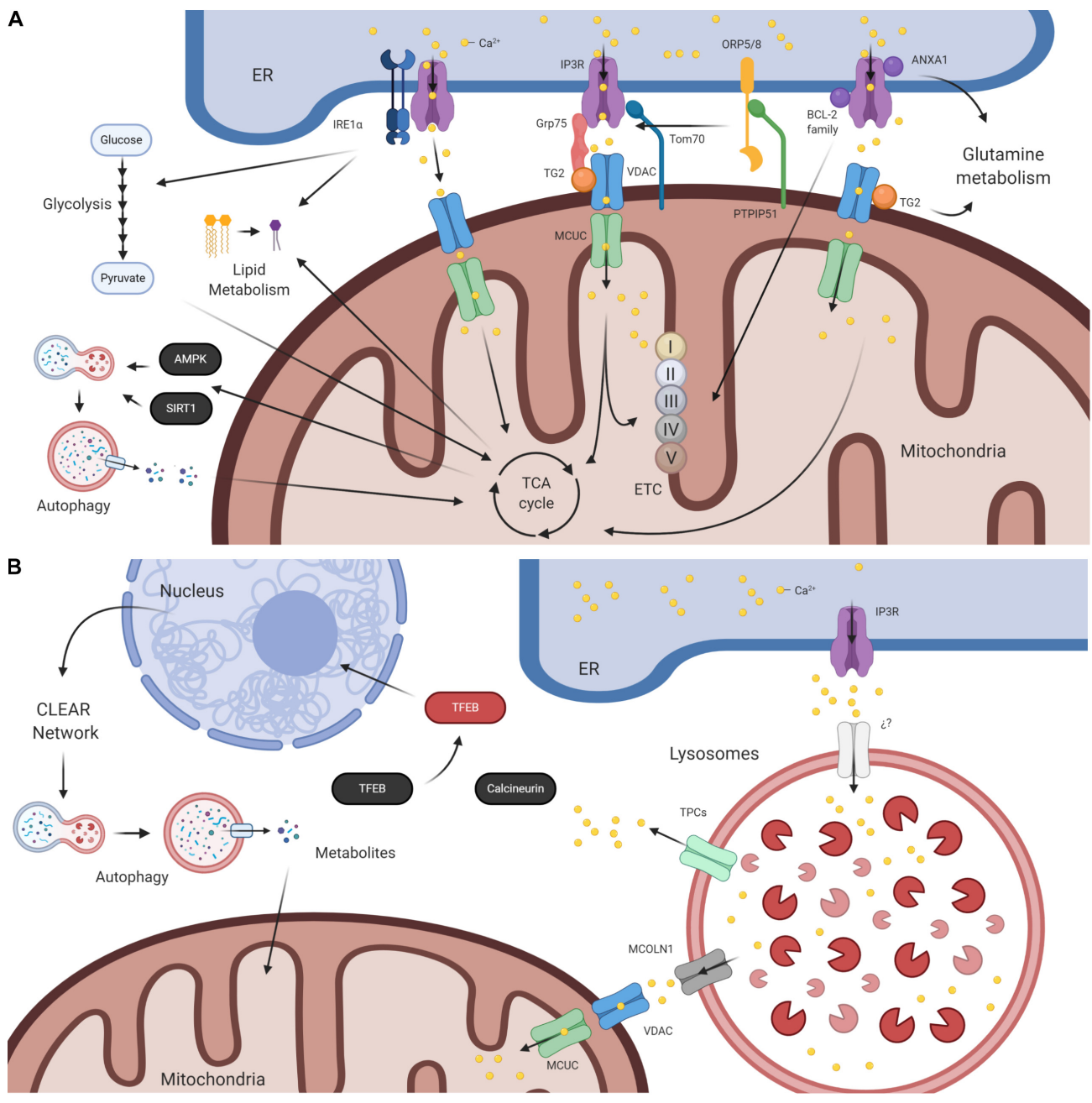

FIGURE 1 | Effects in cellular metabolism of IP3R-mediated $\mathrm{Ca}^{2+}$ release in different membrane contact sites (MCS). (A) IP3R-mediated Ca ${ }^{2+}$ release in mitochondria-endoplasmic reticulum contact sites (MERCS) and its impact on cellular metabolism. Once Ca ${ }^{2+}$ is released from ER through the IP3R, it crosses the outer mitochondrial membrane (OMM) through VDAC and then the inner mitochondrial membrane (IMM) through MCU. TOM70, Grp75, and TG2 work as adaptors for IP3R-VDAC interaction. Additionally, IP3R interacts with proteins regulating $\mathrm{Ca}^{2+}$ release as IRE1a, BCL-2 family proteins, ANXA1, and ORP5/8. Once Ca ${ }^{2+}$ reaches the mitochondrial matrix, it regulates the TCA cycle and ETC complexes. Changes in both affect metabolic pathways as glycolysis, lipid metabolism, and autophagy (see details in the manuscript). (B) IP3R-mediated $\mathrm{Ca}^{2+}$ release from the ER passes through the lysosomal membrane using an unidentified channel (?). Lysosomal $\mathrm{Ca}^{2+}$ release regulates calcineurin activity, which regulates TFEB nuclear translocation. This works as a transcription factor to the CLEAR network, related to genes associated with autophagy and lysosomes. Additionally, $\mathrm{Ca}^{2+}$ release by the lysosomes through MCOLN1 crosses the OMM and the IMM using VDAC and MCU to reach the mitochondrial matrix, hypothetically regulating mitochondrial metabolism (see details in the manuscript). Figure created with BioRender.com. 
that supply many metabolic pathways and in this manner maintain metabolic equilibrium and mitochondrial function (Rabinowitz and White, 2010; Guo et al., 2016; AhumadaCastro et al., 2019). Additionally, the pro-autophagic protein Beclin-1 interacts with IP3R (Vicencio et al., 2009), and its lack of interaction induces autophagy, also contributing to regulating metabolism, but the mechanistic details are still unclear (Decuypere et al., 2011).

Furthermore, lipid accumulations associated with AMPK dephosphorylation have been observed in cellular models with inhibited MCU-dependent mitochondrial $\mathrm{Ca}^{2+}$ uptake. This is mediated by $\mathrm{Ca}^{2+}$-dependent protein phosphatase-4 (PP4) activity (Tomar et al., 2019). However, it remains mostly unclear to what extent lipid metabolism regulates IP3R-mediated $\mathrm{Ca}^{2+}$ fluxes or, vice versa, to what extent these $\mathrm{Ca}^{2+}$ fluxes regulate lipid metabolism via other intermediary proteins. Along these lines, proteins related to lipid transport have been described at the MERCS where they regulate $\mathrm{Ca}^{2+}$ flux between ER and mitochondria (Pulli et al., 2018). Moreover, a preprint from Giordano lab shows that oxysterol-binding proteinrelated proteins (ORP) 5 and 8 physically and functionally interact with MIB/MICOS complexes facilitating the transfer of phosphatidylserine (PS) from the ER to mitochondria (Rochin et al., 2019). In addition, ORP5 interacts with VDAC regulating the mitochondrial $\mathrm{Ca}^{2+}$ uptake at MERCS (Rochin et al., 2019; Figure 1A). Finally, ORP4L has been described extracting and presenting PIP2 to PLC 33 (Zhong et al., 2019), facilitating IP3 generation. Also, ORP4L interaction with IP3R1 regulates its activity (Cao et al., 2019). Expectedly, all these interactions could cause mitochondrial bioenergetic alterations, involving additional metabolic pathways.

In all cases described above, it is not completely understood whether the IP3R isoforms contribute differently to this process. Recently, Bartok et al. (2019) clearly show that IP3R is necessary for ER-mitochondrial contact formation, and re-expression of each of the three isoforms alone was sufficient to restore the MERCs in triple IP3R-deficient (TKO) DT40 cells. Additionally, the authors show that IP3R2 turned out to be the most efficient isoform in delivering $\mathrm{Ca}^{2+}$ into mitochondria (Bartok et al., 2019). This result suggests that IP3R2 is essential for many aspects of cellular metabolism, but more studies need to be performed to clarify if this phenomenon observed in DT40 and HeLa can be extrapolated to other cell types and other physiological contexts.

B-cell lymphoma-2 protein family members, which also interact with the IP3R, have been shown to play a role in mitochondrial metabolism (Chong et al., 2020). In particular, BCL2 regulated oxidative phosphorylation (OXPHOS) at complex IV level (Chen and Pervaiz, 2010), BCL-XL regulated ATP synthase (Alavian et al., 2011), and MCL-1 regulated aspects of mitochondrial dynamics, mitochondrial physiology, and its metabolism (Perciavalle et al., 2012; Escudero et al., 2018; Figure 1A). In addition, TG2 and ANXA1 have been associated with glutamine metabolism (Figure 1A; Nurminskaya and Belkin, 2012) and regulation of reductive carboxylation, respectively (Rohwer et al., 2016). Whether these effects on metabolism are related to their interaction with IP3R and $\mathrm{Ca}^{2+}$ flux is unclear.
Finally, IRE1 $\alpha$, a protein related to ER homeostasis and its response to stress, particularly by the unfolded protein response (UPR) (Hetz et al., 2020), interacts with IP3R and plays a role in cellular metabolism (Figure 1A). Carreras-Sureda et al. (2019) described that IRE1 $\alpha$ interacts with IP3R1, regulating IP3R-mediated $\mathrm{Ca}^{2+}$ release and its position in MERCS and in this manner regulates TCA cycle activity and MERCS. Although IRE1a has been described to regulate aspects of cellular metabolism such as lipid metabolism and glycolysis (Huang et al., 2019; Figure 1A), it is not clear whether this regulation is also mediated by IP3R-mediated $\mathrm{Ca}^{2+}$.

\section{IP3R AT THE ER-LYSOSOME MCS AND CELULLAR METABOLISM}

In a similar way to MERCs, ER establishes membrane contact sites with lysosomes and endosomes, but these have not been completely characterized (Lee and Blackstone, 2020). A stable interaction between ER and early/late endosomes, probably related to the maturation process of these vesicles, has been shown (Friedman et al., 2011; Zajac et al., 2013). In addition, $\mathrm{Ca}^{2+}$ fluxes between these two organelles have been described. In fact, the ER is the most important source of lysosomal $\mathrm{Ca}^{2+}$, which can be delivered by all three IP3R isoforms (Atakpa et al., 2018; Figure 1B). This $\mathrm{Ca}^{2+}$ has been described as one of the counterions that the lysosome utilizes for its acidification (Christensen et al., 2002; Yang et al., 2019). Furthermore, changes in lysosomal $\mathrm{pH}$ generate a redistribution of lysosomes toward other areas of the ER with a lower density of IP3Rs, which finally interrupts this $\mathrm{Ca}^{2+}$ flow (Atakpa et al., 2018). Along with this, autophagy can be regulated by the release of lysosomal $\mathrm{Ca}^{2+}$ stores to cytoplasm, inducing the activity of calcineurin, a $\mathrm{Ca}^{2+}$-dependent phosphatase, which dephosphorylates the transcription factor EB (TFEB) and allows its translocation to the nucleus (Medina et al., 2015; Figure 1B). TFEB is a master regulator of the coordinated lysosomal expression and regulation (CLEAR) network, a gene network associated with the lysosome and autophagy (Palmieri et al., 2011). Another interesting fact described by Cang et al. (2013) pertains to the role of two pore channels (TPCs) on cellular metabolism. TPCs are endosome/lysosome-located ion channels selective to sodium $\left(\mathrm{Na}^{+}\right)$and $\mathrm{Ca}^{2+}$ that form a complex with mTOR. Upon starvation, when mTOR is inhibited, TPCs are actively transferring $\mathrm{Ca}^{2+}$ to the lysosome, which is necessary to maintain the lysosomal $\mathrm{pH}$ and amino acid efflux (Cang et al., 2013). Whether IP3R-mediated $\mathrm{Ca}^{2+}$ release to lysosomes plays a role in its degradative activity or in cellular metabolism is unknown. Interestingly, Peng et al. (2020) have described the occurrence of $\mathrm{Ca}^{2+}$ fluxes between lysosomes and mitochondria, via the lysosomal ion channel MCOLN1 and the mitochondrial transporter VDAC (Figure 1B). Such a discovery opened a new path to target $\mathrm{Ca}^{2+}$ regulation of mitochondrial metabolism for therapeutic purposes. Finally, cholesterol transfer between ER and lysosomes has been described, possibly having implications on low-density lipoprotein (LDL) metabolism (Höglinger et al., 2019). This transfer involves the cholesterol 
sensor oxysterol-binding protein-related protein 1L (ORP1L) and the integral ER proteins VAPA/B proteins (Höglinger et al., 2019). Certainly, the relationships between $\mathrm{Ca}^{2+}$ and lipids associated to lysosomes have been shown before (Van Der Kant and Neefjes, 2014); however, it is still unclear if IP3R $\mathrm{Ca}^{2+}$ release is involved.

\section{IMPLICATIONS IN CANCER}

For oncogenic processes, the rewiring of metabolic networks is an essential step (De Berardinis and Chandel, 2016). Many cancer hallmarks such as migration, invasion, excessive proliferation, apoptosis evasion, and angiogenesis, among others, are sustained by altered metabolism (Ward and Thompson, 2012). Alterations can be evidenced as changes in nutrient consumption (increase glutamine utilization) (Cluntun et al., 2017), changes in mitochondria to favor lipid and nucleotide synthesis to support growth (DeBerardinis et al., 2008), and generation of oncometabolites that favor proliferation and invasion of cancer cells (Sciacovelli and Frezza, 2016).

In all these instances, metabolic rewiring is coupled with modifications of $\mathrm{Ca}^{2+}$ fluxes, particularly those involving the ER $\mathrm{Ca}^{2+}$ store (Zhai et al., 2020). It has been described that pancreatic (Okeke et al., 2016), breast (Singh et al., 2017), colorectal (Pierro et al., 2014), glioblastoma (Kang et al., 2017), gastric (Sakakura et al., 2003), and lung cancers (Bergner et al., 2009) show increases in IP3R isoform levels, IP3R3 being the preponderant isoform (Rezuchova et al., 2019; Rosa et al., 2020), followed by IP3R2 (Vervloessem et al., 2014; Bartok et al., 2019). It could be speculated that these cells have a better mitochondrial metabolism fitness and lysosomal function that provide them with a proliferative and survival advantage.

Additionally, our group has described that cancer cells become "addicted to IP3R-mediated $\mathrm{Ca}^{2+}$ release," which is essential for cancer cell survival (Cárdenas et al., 2017; Cardenas et al., 2020). In this context, it is interesting to note that many anti-apoptotic proteins, such as BCL2, BCL-XL, and MCL1, which are essential for the oncogenic processes, work as IP3R regulators. In addition, oncogenic proteins such as AKT, PML, and PTEN modify IP3R function. AKT, which is overactivated in many cancers, inhibits IP3R-mediated $\mathrm{Ca}^{2+}$ release (Marchi et al., 2012). Mutated PML (as is normally found in cancers) loses its ability to increase IP3Rmediated $\mathrm{Ca}^{2+}$ release (Missiroli et al., 2016). Finally, PTEN (Kuchay et al., 2017) increases IP3R-mediated $\mathrm{Ca}^{2+}$ release through its phosphatase activity. Currently, it is known and well accepted that IP3R-mediated $\mathrm{Ca}^{2+}$ fluxes in cancer are essential for cancer development, but whether specific changes in IP3R isoform patterns occur in different types of cancer has not been studied.

\section{CONCLUDING REMARKS/PERSPECTIVES}

Cancer is a pathology like no other due to the presence of several layers of heterogeneity, which include different tissues and different oncogenic processes (Gerlinger et al., 2012; Venkatesan and Swanton, 2016). For these reasons, the search and development of new drugs capable to cure many types of cancers have been long and difficult. Cellular metabolism appears as a good target to tackle several types of cancer and its regulation by $\mathrm{Ca}^{2+}$ seems to be a good option to develop new drugs (Bustos et al., 2017). Regarding $\mathrm{Ca}^{2+}$, there is accumulated knowledge about the specific role of many ion channels in cancer cell physiology (Marchi et al., 2020). In this context, Xestospongin $\mathrm{B}(\mathrm{XeB})$, an alkaloid obtained from the marine sponge Xestospongia exigua, specifically inhibits IP3R-mediated $\mathrm{Ca}^{2+}$ release (Jaimovich et al., 2005), selectively inducing nonapoptotic cell death of some types of cancer cells (Cárdenas et al., 2017; Cardenas et al., 2020). In this case, $\mathrm{Ca}^{2+}$ flux interruption leads cancer cells into a metabolic and bioenergetic crisis that ends in cell death (Silva-Pavez et al., 2020). Other Xestospongins have been tested too, but they are not as selective as XeB (Gambardella et al., 2020). Similarly, the inhibition of the IP3 generation by ORP4L with the compound LYZ-81 has been shown to eradicate leukemia stem cells in a selective manner (Zhong et al., 2019). Another molecule tested to blunt the activity of the IP3R is the non-specific inhibitor, 2-aminoethoxydiphenyl borate (2APB), which induces apoptosis in gastric cancer cells through an unexplored mechanism (Sakakura et al., 2003). Along with the three cases mentioned above, there are other molecules that have been developed as IP3R inhibitors that need to be tested as potential anti-tumor drugs (Gambardella et al., 2020). On the other hand, several molecules and peptides have been tested and shown to activate IP3R-mediated $\mathrm{Ca}^{2+}$ release generating an overwhelming transfer of $\mathrm{Ca}^{2+}$ to mitochondria. These high $\mathrm{Ca}^{2+}$ concentrations induce apoptosis or sensitize cancer cells to chemotherapeutic drugs such as Bcl-2/IP3R Disruptor2 (BIRD-2), which is a peptide (Bittremieux et al., 2019), and GGTi-2418, a geranylgeranyl transferase inhibitor of FBXL2 (Kuchay et al., 2017).

In all cases mentioned above, IP3Rs have emerged as essential $\mathrm{Ca}^{2+}$ channels for cancer cell survival. How different IP3R isoforms - homotetramers or heterotetramers - contribute to cancer development remains an area of research that requires more exploration. A better understanding of IP3R regulation and its effects on metabolism in normal and cancer cells will help to develop new therapeutic strategies to fight this devastating set of diseases in the future.

\section{AUTHOR CONTRIBUTIONS}

UA-C and CC designed and outlined the structure and contents of the review. UA-C, GB, ES-P, AP-H, AL, and CC contributed to the literature review, discussion, and writing of the manuscript. All authors contributed to manuscript revision and approved the version to be published.

\section{FUNDING}

This work was supported by the ANID/FONDECYT \# 1200255 (CC) and ANID/FONDAP \#15150012 (UA-C, CC, and AL). 


\section{REFERENCES}

Ahumada-Castro, U., Silva-Pavez, E., Lovy, A., Pardo, E., Molgü, J., and Cárdenas, C. (2019). MTOR-independent autophagy induced by interrupted endoplasmic reticulum-mitochondrial $\mathrm{Ca} 2+$ communication: a dead end in cancer cells. Autophagy 15, 358-361. doi: 10.1080/15548627.2018.1537769

Alavian, K. N., Li, H., Collis, L., Bonanni, L., Zeng, L., Sacchetti, S., et al. (2011). $\mathrm{Bcl}-\mathrm{x} \mathrm{L}$ regulates metabolic efficiency of neurons through interaction with the mitochondrial F1 FO ATP synthase. Nat. Cell Biol. 13, 1224-1233. doi: 10.1038/ ncb2330

Alzayady, K. J., Wang, L., Chandrasekhar, R., Wagner, L. E., Van Petegem, F., and Yule, D. I. (2016). Defining the stoichiometry of inositol 1,4,5-trisphosphate binding required to initiate Ca2+ release. Sci. Signal. 9:ra35. doi: 10.1126/ scisignal.aad6281

Atakpa, P., Thillaiappan, N. B., Mataragka, S., Prole, D. L., and Taylor, C. W. (2018). IP3 receptors preferentially associate with ER-lysosome contact sites and selectively deliver Ca2+ to lysosomes. Cell Rep. 25, 3180-3193. doi: 10.1016/j. celrep.2018.11.064

Bartok, A., Weaver, D., Golenár, T., Nichtova, Z., Katona, M., Bánsághi, S., et al. (2019). IP3 receptor isoforms differently regulate ER-mitochondrial contacts and local calcium transfer. Nat. Commun. 10:3726. doi: 10.1038/s41467-01911646-3

Bergner, A., Kellner, J., Tufman, A., and Huber, R. M. (2009). Endoplasmic reticulum Ca2+-homeostasis is altered in small and non-small cell lung cancer cell lines. J. Exp. Clin. Cancer Res. 28, 25. doi: 10.1186/1756-9966-28-25

Berridge, M. J., Bootman, M. D., and Roderick, H. L. (2003). Calcium signalling: dynamics, homeostasis and remodelling. Nat. Rev. Mol. Cell Biol. 4, 517-529. doi: $10.1038 / \mathrm{nrm} 1155$

Berridge, M. J., Lipp, P., and Bootman, M. D. (2000). The versatility and universality of calcium signalling. Nat. Rev. Mol. Cell Biol. 1, 11-21. doi: 10. $1038 / 35036035$

Bittremieux, M., La Rovere, R. M., Akl, H., Martines, C., Welkenhuyzen, K., Dubron, K., et al. (2019). Constitutive IP 3 signaling underlies the sensitivity of B-cell cancers to the Bcl-2/IP 3 receptor disruptor BIRD-2. Cell Death Differ. 26, 531-547. doi: 10.1038/s41418-018-0142-3

Boehning, D., Mak, D. O. D., Foskett, J. K., and Joseph, S. K. (2001). Molecular determinants of ion permeation and selectivity in inositol 1,4,5-trisphosphate receptor Ca2+ channels. J. Biol. Chem. 276, 13509-13512. doi: 10.1074/jbc. C100094200

Bonneau, B., Ando, H., Kawaai, K., Hirose, M., Takahashi-Iwanaga, H., and Mikoshiba, K. (2016). IRBIT controls apoptosis by interacting with the Bcl-2 homolog, Bcl2110, and by promoting ER-mitochondria contact. eLife 5:e19896. doi: $10.7554 /$ eLife. 19896

Bootman, M. D., and Bultynck, G. (2020). Fundamentals of cellular calcium signaling: a primer. Cold Spring Harb. Perspect. Biol. 12:a038802. doi: 10.1101/ cshperspect.a038802

Bustos, G., Cruz, P., Lovy, A., and Cárdenas, C. (2017). Endoplasmic reticulummitochondria calcium communication and the regulation of mitochondrial metabolism in cancer, a novel potential target. Front. Oncol. 7:199. doi: 10.3389/ fonc.2017.00199/abstract

Bygrave, F. L. (1967). The ionic environment and metabolic control. Nature 214, 667-671. doi: 10.1038/214667a0

Cang, C., Zhou, Y., Navarro, B., Seo, Y. J., Aranda, K., Shi, L., et al. (2013). MTOR regulates lysosomal ATP-sensitive two-pore $\mathrm{Na}+$ channels to adapt to metabolic state. Cell 152, 778-790. doi: 10.1016/j.cell.2013.01.023

Cao, X., Chen, J., Li, D., Xie, P., Xu, M., Lin, W., et al. (2019). ORP4L couples IP3 to ITPR1 in control of endoplasmic reticulum calcium release. FASEB J. 33, 13852-13865. doi: 10.1096/fj.201900933RR

Cárdenas, C., Escobar, M., García, A., Osorio-Reich, M., Härtel, S., Foskett, J. K., et al. (2010a). Visualization of inositol 1,4,5-trisphosphate receptors on the nuclear envelope outer membrane by freeze-drying and rotary shadowing for electron microscopy. J. Struct. Biol. 171, 372-381. doi: 10.1016/j.jsb.2010.05.003

Cardenas, C., Lovy, A., Silva-Pavez, E., Urra, F., Mizzoni, C., Ahumada-Castro, U., et al. (2020). Cancer cells with defective oxidative phosphorylation require endoplasmic reticulum-to-mitochondria Ca2+transfer for survival. Sci. Signal. 13:eaay1212. doi: 10.1126/scisignal.aay1212

Cárdenas, C., Miller, R. A., Smith, I., Bui, T., Molgo, J., Muller, M., et al. (2010b). Essential regulation of cell bioenergetics by constitutive InsP3 receptor Ca2+ transfer to mitochondria. Cell 142, 270-283. doi: 10.1016/j.cell.2010. 06.007
Cárdenas, C., Müller, M., McNeal, A., Lovy, A., Jaňa, F., Bustos, G., et al. (2017). Selective vulnerability of cancer cells by inhibition of Ca2+ transfer from endoplasmic reticulum to mitochondria. Cell Rep. 14, 2313-2324. doi: 10.1016/ j.celrep.2016.02.030

Carreras-Sureda, A., Jaña, F., Urra, H., Durand, S., Mortenson, D. E., Sagredo, A., et al. (2019). Non-canonical function of IRE1 $\alpha$ determines mitochondriaassociated endoplasmic reticulum composition to control calcium transfer and bioenergetics. Nat. Cell Biol. 21, 755-767. doi: 10.1038/s41556-019-0 329-y

Cattaneo, F., Guerra, G., Parisi, M., De Marinis, M., Tafuri, D., Cinelli, M., et al. (2014). Cell-surface receptors transactivation mediated by G protein-coupled receptors. Int. J. Mol. Sci. 15, 19700-19728. doi: 10.3390/ijms151119700

Chandrasekhar, R., Alzayady, K. J., Wagner, L. E., and Yule, D. I. (2016). Unique regulatory properties of heterotetrameric inositol 1,4, 5-trisphosphate receptors revealed by studying concatenated receptor constructs. J. Biol. Chem. 291, 4846-4860. doi: 10.1074/jbc.M115.705301

Chen, R., Valencia, I., Zhong, F., McColl, K. S., Roderick, H. L., Bootman, M. D., et al. (2004). Bcl-2 functionally interacts with inositol 1,4,5-trisphosphate receptors to regulate calcium release from the ER in response to inositol 1,4,5-trisphosphate. J. Cell Biol. 166, 193-203. doi: 10.1083/jcb.200309146

Chen, Z. X., and Pervaiz, S. (2010). Involvement of cytochrome c oxidase subunits $\mathrm{Va}$ and $\mathrm{Vb}$ in the regulation of cancer cell metabolism by Bcl-2. Cell Death Differ. 17, 408-420. doi: 10.1038/cdd.2009.132

Chong, S. J. F., Marchi, S., Petroni, G., Kroemer, G., Galluzzi, L., and Pervaiz, S. (2020). Noncanonical cell fate regulation by Bcl-2 proteins. Trends Cell Biol. 30, 537-555. doi: 10.1016/j.tcb.2020.03.004

Christensen, K. A., Myers, J. T., and Swanson, J. A. (2002). pH-dependent regulation of lysosomal calcium in macrophages. J. Cell Sci. 115, 599-607.

Clapham, D. E. (2007). Calcium signaling. Cell 131, 1047-1058. doi: 10.1016/j.cell. 2007.11.028

Cluntun, A. A., Lukey, M. J., Cerione, R. A., and Locasale, J. W. (2017). Glutamine metabolism in cancer: understanding the heterogeneity. Trends Cancer 3, 169-180. doi: 10.1016/j.trecan.2017.01.005

Csordás, G., Weaver, D., and Hajnóczky, G. (2018). Endoplasmic reticulummitochondrial contactology: structure and signaling functions. Trends Cell Biol. 28, 523-540. doi: 10.1016/j.tcb.2018.02.009

De Berardinis, R. J., and Chandel, N. S. (2016). Fundamentals of cancer metabolism. Sci. Adv. 2:e1600200. doi: 10.1126/sciadv.1600200

De Smedt, H., Missiaen, L., Parys, J. B., Henning, R. H., Sienaert, I., Vanlingen, S., et al. (1997). Isoform diversity of the inositol trisphosphate receptor in cell types of mouse origin. Biochem. J. 322, 575-583. doi: 10.1042/bj3220575

De Stefani, D., Rizzuto, R., and Pozzan, T. (2016). Enjoy the trip: calcium in mitochondria back and forth. Annu. Rev. Biochem. 85, 161-192. doi: 10.1146/ annurev-biochem-060614-034216

DeBerardinis, R. J., Lum, J. J., Hatzivassiliou, G., and Thompson, C. B. (2008). The biology of cancer: metabolic reprogramming fuels cell growth and proliferation. Cell Metab. 7, 11-20. doi: 10.1016/j.cmet.2007.10.002

Decuypere, J. P., Welkenhuyzen, K., Luyten, T., Ponsaerts, R., Dewaele, M., Molgó, J., et al. (2011). Ins (1,4,5) $\mathrm{P} 3$ receptor-mediated Ca2+ signaling and autophagy induction are interrelated. Autophagy 7, 1472-1489. doi: 10.4161/auto.7.12. 17909

D’Eletto, M., Rossin, F., Occhigrossi, L., Farrace, M. G., Faccenda, D., Desai, R., et al. (2018). Transglutaminase type 2 regulates ER-mitochondria contact sites by interacting with GRP75. Cell Rep. 25, 3573-3581. doi: 10.1016/j.celrep.2018. 11.094

Denton, R. M. (2009). Regulation of mitochondrial dehydrogenases by calcium ions. Biochim. Biophys. Acta 1787, 1309-1316. doi: 10.1016/j.bbabio.2009.01. 005

DeSouza, N., Cui, J., Dura, M., McDonald, T. V., and Marks, A. R. (2007). A function for tyrosine phosphorylation of type 1 inositol 1,4,5-trisphosphate receptor in lymphocyte activation. J. Cell Biol. 179, 923-934. doi: 10.1083/jcb. 200708200

Eckenrode, E. F., Yang, J., Velmurugan, G. V., Kevin Foskett, J., and White, C. (2010). Apoptosis protection by $\mathrm{Mcl}-1$ and Bcl-2 modulation of inositol 1,4,5-trisphosphate receptor-dependent Ca2+ signaling. J. Biol. Chem. 285, 13678-13684. doi: 10.1074/jbc.M109.096040

Escudero, S., Zaganjor, E., Lee, S., Mill, C. P., Morgan, A. M., Crawford, E. B., et al. (2018). Dynamic regulation of long-chain fatty acid oxidation by a noncanonical interaction between the MCL-1 BH3 Helix and VLCAD. Mol. Cell 69, 729-743. doi: 10.1016/j.molcel.2018.02.005 
Filadi, R., Leal, N. S., Schreiner, B., Rossi, A., Dentoni, G., Pinho, C. M., et al. (2018). TOM70 sustains cell bioenergetics by promoting IP3R3-mediated ER to mitochondria Ca2+ transfer. Curr. Biol. 28, 369-382. doi: 10.1016/j.cub.2017. 12.047

Foskett, J. K., White, C., Cheung, K. H., and Mak, D. O. D. (2007). Inositol trisphosphate receptor Ca2+ release channels. Physiol. Rev. 87, 593-658. doi: 10.1152/physrev.00035.2006

Friedman, J. R., Lackner, L. L., West, M., DiBenedetto, J. R., Nunnari, J., and Voeltz, G. K. (2011). ER tubules mark sites of mitochondrial division. Science 334, 358-362. doi: 10.1126/science. 1207385

Furuichi, T., Simon-Chazottes, D., Fujino, I., Yamada, N., Hasegawa, M., Miyawaki, A., et al. (1993). Widespread expression of inositol 1,4,5-trisphosphate receptor type 1 gene (Insp3r1) in the mouse central nervous system. Recept. Channels 1 , $11-24$.

Gambardella, J., Morelli, M. B., Wang, X., Castellanos, V., Mone, P., and Santulli, G. (2020). The discovery and development of IP3 receptor modulators: an update. Expert Opin. Drug Discov. 1-10. doi: 10.1080/17460441.2021.1858792

Gerlinger, M., Rowan, A. J., Horswell, S., Larkin, J., Endesfelder, D., Gronroos, E., et al. (2012). Intratumor heterogeneity and branched evolution revealed by multiregion sequencing. N. Engl. J. Med. 366, 883-892. doi: 10.1056/ NEJMoa1113205

Glancy, B., and Balaban, R. S. (2012). Role of mitochondrial Ca2+ in the regulation of cellular energetics. Biochemistry 51, 2959-2973. doi: 10.1021/bi2018909

Gordaliza-Alaguero, I., Cantó, C., and Zorzano, A. (2019). Metabolic implications of organelle-mitochondria communication. EMBO Rep. 20:e47928. doi: 10. 15252/embr.201947928

Guo, J. Y., Teng, X., Laddha, S. V., Ma, S., Van Nostrand, S. C., Yang, Y., et al. (2016). Autophagy provides metabolic substrates to maintain energy charge and nucleotide pools in Ras-driven lung cancer cells. Genes Dev. 30, 1704-1717. doi: $10.1101 / \mathrm{gad} .283416 .116$

Hetz, C., Zhang, K., and Kaufman, R. J. (2020). Mechanisms, regulation and functions of the unfolded protein response. Nat. Rev. Mol. Cell Biol. 21, 421-438. doi: 10.1038/s41580-020-0250-z

Higo, T., Hattori, M., Nakamura, T., Natsume, T., Michikawa, T., and Mikoshiba, K. (2005). Subtype-specific and ER lumenal environment-dependent regulation of inositol 1,4,5-trisphosphate receptor type 1 by ERp44. Cell 120, 85-98. doi: 10.1016/j.cell.2004.11.048

Höglinger, D., Burgoyne, T., Sanchez-Heras, E., Hartwig, P., Colaco, A., Newton, J., et al. (2019). NPC1 regulates ER contacts with endocytic organelles to mediate cholesterol egress. Nat. Commun. 10:4276. doi: 10.1038/s41467-019-12152-2

Honrath, B., Metz, I., Bendridi, N., Rieusset, J., Culmsee, C., and Dolga, A. M. (2017). Glucose-regulated protein 75 determines ER-mitochondrial coupling and sensitivity to oxidative stress in neuronal cells. Cell Death Discov. 3:17076. doi: 10.1038/cddiscovery.2017.76

Huang, S., Xing, Y., and Liu, Y. (2019). Emerging roles for the ER stress sensor IRE1 in metabolic regulation and disease. J. Biol. Chem. 294, 18726-18741. doi: 10.1074/jbc.REV119.007036

Iwai, M., Michikawa, T., Bosanac, I., Ikura, M., and Mikoshiba, K. (2007). Molecular basis of the isoform-specific ligand-binding affinity of inositol 1,4,5trisphosphate receptors. J. Biol. Chem. 282, 12755-12764. doi: 10.1074/jbc. M609833200

Jaimovich, E., Mattei, C., Liberona, J. L., Cardenas, C., Estrada, M., Barbier, J., et al. (2005). Xestospongin B, a competitive inhibitor of IP3-mediated Ca $2+$ signalling in cultured rat myotubes, isolated myonuclei, and neuroblastoma (NG108-15) cells. FEBS Lett. 579, 2051-2057. doi: 10.1016/j.febslet.2005.02.053

Kang, S., Hong, J., Lee, J. M., Moon, H. E., Jeon, B., Choi, J., et al. (2017). Trifluoperazine, a well-known antipsychotic, inhibits glioblastoma invasion by binding to calmodulin and disinhibiting calcium release channel IP3R. Mol. Cancer Ther. 16, 217-227. doi: 10.1158/1535-7163.MCT-16-0169-T

Klar, J., Hisatsune, C., Baig, S. M., Tariq, M., Johansson, A. C. V., Rasool, M., et al. (2014). Abolished InsP3R2 function inhibits sweat secretion in both humans and mice. J. Clin. Invest. 124, 4773-4780. doi: 10.1172/JCI70720

Kuchay, S., Giorgi, C., Simoneschi, D., Pagan, J., Missiroli, S., Saraf, A., et al. (2017). PTEN counteracts FBXL2 to promote IP3R3- and Ca 2+-mediated apoptosis limiting tumour growth. Nature 546, 554-558. doi: 10.1038/nature22965

La Rovere, R. M. L., Roest, G., Bultynck, G., and Parys, J. B. (2016). Intracellular $\mathrm{Ca} 2+$ signaling and $\mathrm{Ca} 2+$ microdomains in the control of cell survival, apoptosis and autophagy. Cell Calc. 60, 74-87. doi: 10.1016/j.ceca.2016.04.005
Lanner, J. T., Georgiou, D. K., Joshi, A. D., and Hamilton, S. L. (2010). Ryanodine receptors: structure, expression, molecular details, and function in calcium release. Cold Spring Harb. Perspect. Biol. 2, 1-21. doi: 10.1101/cshperspect. a003996

Lee, C. A., and Blackstone, C. (2020). ER morphology and endo-lysosomal crosstalk: functions and disease implications. Biochim. Biophys. Acta Mol. Cell Biol. Lipids 1865:158544. doi: 10.1016/j.bbalip.2019.158544

Lovy, A., Ahumada-Castro, U., Bustos, G., Farias, P., Gonzalez-Billault, C., Molgó, J., et al. (2020). Concerted action of AMPK and Sirtuin-1 induces mitochondrial fragmentation upon inhibition of $\mathrm{Ca} 2+$ transfer to mitochondria. Front. Cell Dev. Biol. 8:378. doi: 10.3389/fcell.2020.00378

Mak, D. O. D., and Foskett, J. K. (2015). Inositol 1,4,5-trisphosphate receptors in the endoplasmic reticulum: a single-channel point of view. Cell Calc. 58, 67-78. doi: 10.1016/j.ceca.2014.12.008

Marchi, S., Giorgi, C., Galluzzi, L., and Pinton, P. (2020). Ca2+ fluxes and cancer. Mol. Cell 78, 1055-1069. doi: 10.1016/j.molcel.2020.04.017

Marchi, S., Marinello, M., Bononi, A., Bonora, M., Giorgi, C., Rimessi, A., et al. (2012). Selective modulation of subtype III IP3R by Akt regulates ER Ca2+ release and apoptosis. Cell Death Dis. 3:e304. doi: 10.1038/cddis.2012.45

Medina, D. L., Di Paola, S., Peluso, I., Armani, A., De Stefani, D., Venditti, R., et al. (2015). Lysosomal calcium signalling regulates autophagy through calcineurin and TFEB. Nat. Cell Biol. 17, 288-299. doi: 10.1038/ncb3114

Mikoshiba, K. (2007). IP3 receptor/Ca2+ channel: from discovery to new signaling concepts. J. Neurochem. 102, 1426-1446. doi: 10.1111/j.1471-4159.2007. 04825.x

Mikoshiba, K. (2015). Role of IP3 receptor signaling in cell functions and diseases. Adv. Biol. Regul. 57, 217-227. doi: 10.1016/j.jbior.2014.10.001

Missiroli, S., Bonora, M., Patergnani, S., Poletti, F., Perrone, M., Gafà, R., et al. (2016). PML at mitochondria-associated membranes is critical for the repression of autophagy and cancer development. Cell Rep. 16, 2415-2427. doi: 10.1016/j.celrep.2016.07.082

Monkawa, T., Miyawaki, A., Sugiyama, T., Yoneshima, H., Yamamoto-Hino, M., Furuichi, T., et al. (1995). Heterotetrameric complex formation of inositol 1,4,5trisphosphate receptor subunits. J. Biol. Chem. 270, 14700-14704. doi: 10.1074/ jbc. 270.24 .14700

Muchowska, K. B., Varma, S. J., and Moran, J. (2020). Nonenzymatic metabolic reactions and life's origins. Chem. Rev. 120, 7708-7744. doi: 10.1021/acs. chemrev.0c00191

Nakade, S., Maeda, N., and Mikoshiba, K. (1991). Involvement of the C-terminus of the inositol 1,4,5-trisphosphate receptor in $\mathrm{Ca} 2+$ release analysed using region-specific monoclonal antibodies. Biochem. J. 277, 125-131. doi: 10.1042/ bj2770125

Nakagawa, T., Okano, H., Furuichi, T., Aruga, J., and Mikoshiba, K. (1991). The subtypes of the mouse inositol 1,4,5-trisphosphate receptor are expressed in a tissue-specific and developmentally specific manner. Proc. Natl. Acad. Sci. U.S.A. 88, 6244-6248. doi: 10.1073/pnas.88.14.6244

Nakamura, Y., and Fukami, K. (2017). Regulation and physiological functions of mammalian phospholipase C. J. Biochem. 161, 315-321. doi: 10.1093/jb/ mvw094

Narayanan, D., Adebiyi, A., and Jaggar, J. H. (2012). Inositol trisphosphate receptors in smooth muscle cells. Am. J. Physiol. Hear. Circ. Physiol. 302, H2190-H2210. doi: 10.1152/ajpheart.01146.2011

Nurminskaya, M. V., and Belkin, A. M. (2012). Cellular functions of tissue transglutaminase. Int. Rev. Cell Mol. Biol. 294, 1-97. doi: 10.1016/B978-0-12394305-7.00001-X

Okeke, E., Parker, T., Dingsdale, H., Concannon, M., Awais, M., Voronina, S., et al. (2016). Epithelial-mesenchymal transition, IP3 receptors and ERPM junctions: translocation of $\mathrm{Ca} 2+$ signalling complexes and regulation of migration. Biochem. J. 473, 757-767. doi: 10.1042/BJ20150364

Palmieri, M., Impey, S., Kang, H., di Ronza, A., Pelz, C., Sardiello, M., et al. (2011). Characterization of the CLEAR network reveals an integrated control of cellular clearance pathways. Hum. Mol. Genet. 20, 3852-3866. doi: 10.1093/ hmg/ddr306

Parys, J. B., and De Smedt, H. (2012). Inositol 1,4,5-trisphosphate and its receptors. Adv. Exp. Med. Biol. 740, 255-279. doi: 10.1007/978-94-007-2888-2_11

Patterson, R. L., Boehning, D., and Snyder, S. H. (2004). Inositol 1,4,5-trisphosphate receptors as signal integrators. Annu. Rev. Biochem. 73, 437-465. doi: 10.1146/ annurev.biochem.73.071403.161303 
Peng, W., Wong, Y. C., and Krainc, D. (2020). Mitochondria-lysosome contacts regulate mitochondrial $\mathrm{Ca} 2+$ dynamics via lysosomal TRPML1. Proc. Natl. Acad. Sci. U.S.A. 117, 19266-19275. doi: 10.1073/pnas.2003236117

Perciavalle, R. M., Stewart, D. P., Koss, B., Lynch, J., Milasta, S., Bathina, M., et al. (2012). Anti-apoptotic MCL-1 localizes to the mitochondrial matrix and couples mitochondrial fusion to respiration. Nat. Cell Biol. 14, 575-583. doi: $10.1038 /$ ncb2488

Pierro, C., Cook, S. J., Foets, T. C. F., Bootman, M. D., and Roderick, H. L. (2014). Oncogenic K-Ras suppresses IP3-dependent Ca2+ release through remodelling of the isoform composition of IP3Rs and ER luminal Ca2+levels in colorectal cancer cell lines. J. Cell Sci. 127, 1607-1619. doi: 10.1242/jcs.141408

Prinz, W. A., Toulmay, A., and Balla, T. (2020). The functional universe of membrane contact sites. Nat. Rev. Mol. Cell Biol. 21, 7-24. doi: 10.1038/s41580019-0180-9

Prole, D. L., and Taylor, C. W. (2019). Structure and function of IP3 receptors. Cold Spring Harb. Perspect. Biol. 11:a035063. doi: 10.1101/cshperspect.a035063

Pulli, I., Lassila, T., Pan, G., Yan, D., Olkkonen, V. M., and Törnquist, K. (2018). Oxysterol-binding protein related-proteins (ORPs) 5 and 8 regulate calcium signaling at specific cell compartments. Cell Calc. 72, 62-69. doi: 10.1016/j.ceca. 2018.03.001

Rabinowitz, J. D., and White, E. (2010). Autophagy and metabolism. Science 330, 1344-1348. doi: 10.1126/science.1193497

Rezuchova, I., Hudecova, S., Soltysova, A., Matuskova, M., Durinikova, E., Chovancova, B., et al. (2019). Type 3 inositol 1,4,5-trisphosphate receptor has antiapoptotic and proliferative role in cancer cells. Cell Death Dis. 10:186. doi: 10.1038/s41419-019-1433-4

Rochin, L., Sauvanet, C., Jääskeläinen, E., Houcine, A., Kivelä, A., Xingjie, M. A., et al. (2019). Orp5 transfers phosphatidylserine to mitochondria and regulates mitochondrial calcium uptake at endoplasmic reticulum-mitochondria contact sites. bioRxiv [Preprint]. doi: 10.1101/695577

Rohwer, N., Bindel, F., Grimm, C., Lin, S. J., Wappler, J., Klinger, B., et al. (2016). Annexin A1 sustains tumor metabolism and cellular proliferation upon stable loss of HIF1A. Oncotarget 7, 6693-6710. doi: 10.18632/oncotarget.6793

Rosa, N., Sneyers, F., Parys, J. B., and Bultynck, G. (2020). Type 3 IP3 receptors: the chameleon in cancer. Int. Rev. Cell Mol. Biol. 351, 101-148. doi: 10.1016/bs. ircmb.2020.02.003

Sakakura, C., Hagiwara, A., Fukuda, K., Shimomura, K., Takagi, T., Kin, S., et al. (2003). Possible involvement of inositol 1,4,5-trisphosphate receptor type 3 (IP3R3) in the peritoneal dissemination of gastric cancers. Anticancer Res. 23, 3691-3697.

Sciacovelli, M., and Frezza, C. (2016). Oncometabolites: unconventional triggers of oncogenic signalling cascades. Free Radic. Biol. Med. 100, 175-181. doi: 10.1016/j.freeradbiomed.2016.04.025

Scorrano, L., De Matteis, M. A., Emr, S., Giordano, F., Hajnóczky, G., Kornmann, B., et al. (2019). Coming together to define membrane contact sites. Nat. Commun. 10:1287. doi: 10.1038/s41467-019-09253-3

Serysheva, I. I. (2014). Toward a high-resolution structure of IP3R channel. Cell Calc. 56, 125-132. doi: 10.1016/j.ceca.2014.08.002

Shkryl, V. M. (2017). Intracellular calcium fluxes in excitable cells. Neurophysiology 49, 384-392. doi: 10.1007/s11062-018-9698-2

Silva-Pavez, E., Ahumada-Castro, U., Lovy, A., and Cárdenas, J. C. (2020). Ca2+ transfer to mitochondria: a spark of life in unexpected conditions. Mol. Cell. Oncol. 8:1839341. doi: 10.1080/23723556.2020.1839341

Singh, A., Sharma, R. K., Chagtoo, M., Agarwal, G., George, N., Sinha, N., et al. (2017). 1H NMR metabolomics reveals association of high expression of inositol 1, 4, 5 trisphosphate receptor and metabolites in breast cancer patients. PLoS One 12:e0169330. doi: 10.1371/journal.pone.0169330

Szabadkai, G., Bianchi, K., Várnai, P., De Stefani, D., Wieckowski, M. R., Cavagna, D., et al. (2006). Chaperone-mediated coupling of endoplasmic reticulum and mitochondrial Ca2+ channels. J. Cell Biol. 175, 901-911. doi: 10.1083/jcb. 200608073

Szado, T., Vanderheyden, V., Parys, J. B., De Smedt, H., Rietdorf, K., Kotelevets, L., et al. (2008). Phosphorylation of inositol 1,4,5-trisphosphate receptors by protein kinase B/Akt inhibits Ca2+ release and apoptosis. Proc. Natl. Acad. Sci. U.S.A. 105, 2427-2432. doi: 10.1073/pnas.0711324105

Tomar, D., Jaña, F., Dong, Z., Quinn, W. J., Jadiya, P., Breves, S. L., et al. (2019). Blockade of MCU-mediated Ca 2+ uptake perturbs lipid metabolism via PP4dependent AMPK dephosphorylation. Cell Rep. 26, 3709-3725. doi: 10.1016/j. celrep.2019.02.107
Tu, H., Wang, Z., and Bezprozvanny, I. (2005). Modulation of mammalian inositol $1,4,5$-trisphosphate receptor isoforms by calcium: a role of calcium sensor region. Biophys. J. 88, 1056-1069. doi: 10.1529/biophysj.104.049601

Uchida, K., Miyauchi, H., Furuichi, T., Michikawa, T., and Mikoshiba, K. (2003). Critical regions for activation gating of the inositol 1,4,5-trisphosphate receptor. J. Biol. Chem. 278, 16551-16560. doi: 10.1074/jbc.M300646200

Vais, H., Wang, M., Mallilankaraman, K., Payne, R., McKennan, C., Lock, J. T., et al. (2020). ER-luminal $[\mathrm{ca} 2+]$ regulation of insp3 receptor gating mediated by an er-luminal peripheral ca2+-binding protein. eLife 9:e53531. doi: 10.7554/eLife. 53531

Van Der Kant, R., and Neefjes, J. (2014). Small regulators, major consequences$\mathrm{Ca} 2+$ and cholesterol at the endosome-ER interface. J. Cell Sci. 127, 929-938. doi: $10.1242 /$ jcs. 137539

Venkatesan, S., and Swanton, C. (2016). Tumor evolutionary principles: how intratumor heterogeneity influences cancer treatment and outcome. Am. Soc. Clin. Oncol. Educ. B. 35, e141-e149. doi: 10.1200/edbk_158930

Vermassen, E., Parys, J. B., and Mauger, J. P. (2004). Subcellular distribution of the inositol 1,4,5-trisphosphate receptors: functional relevance and molecular determinants. Biol. Cell 96, 3-17. doi: 10.1016/j.biolcel.2003.11.004

Vervloessem, T., Yule, D. I., Bultynck, G., and Parys, J. B. (2014). The type 2 inositol 1,4,5-trisphosphate receptor, emerging functions for an intriguing Ca2+-release channel. Biochim. Biophys. Acta - Mol. Cell Res. 1853, 1992-2005. doi: 10.1016/j.bbamcr.2014.12.006

Vicencio, J. M., Ortiz, C., Criollo, A., Jones, A. W. E., Kepp, O., Galluzzi, L., et al. (2009). The inositol 1,4,5-trisphosphate receptor regulates autophagy through its interaction with Beclin 1. Cell Death Differ. 16, 1006-1017. doi: 10.1038/cdd. 2009.34

Wagner, L. E., and Yule, D. I. (2012). Differential regulation of the InsP3 receptor type-1 and -2 single channel properties by InsP3, Ca2+ and ATP. J. Physiol. 590, 3245-3259. doi: 10.1113/jphysiol.2012.228320

Ward, P. S., and Thompson, C. B. (2012). Metabolic reprogramming: a cancer hallmark even warburg did not anticipate. Cancer Cell 21, 297-308. doi: 10. 1016/j.ccr.2012.02.014

White, C., Li, C., Yang, J., Petrenko, N. B., Madesh, M., Thompson, C. B., et al. (2005). The endoplasmic reticulum gateway to apoptosis by Bcl-XL modulation of the InsP3R. Nat. Cell Biol. 7, 1021-1028. doi: 10.1038/ncb1302

Wojcikiewicz, R. J. H. (1995). Type I, II, and III inositol 1,4,5-trisphosphate receptors are unequally susceptible to down-regulation and are expressed in markedly different proportions in different cell types. J. Biol. Chem. 270, 11678-11683. doi: 10.1074/jbc.270.19.11678

Wu, H., Carvalho, P., and Voeltz, G. K. (2018). Here, there, and everywhere: the importance of ER membrane contact sites. Science 361:eaan5835. doi: 10.1126/ science.aan 5835

Yang, J., Zhao, Z., Gu, M., Feng, X., and Xu, H. (2019). Release and uptake mechanisms of vesicular Ca 2+ stores. Protein Cell 10, 8-19. doi: 10.1007/ s13238-018-0523-X

Zajac, A. L., Goldman, Y. E., Holzbaur, E. L. F., and Ostap, E. M. (2013). Local cytoskeletal and organelle interactions impact molecular-motor-driven early endosomal trafficking. Curr. Biol. 23, 1173-1180. doi: 10.1016/j.cub.2013.05. 015

Zhai, X., Sterea, A. M., and El Hiani, Y. (2020). Lessons from the endoplasmic reticulum Ca2+ transporters-a cancer connection. Cells 9:1536. doi: 10.3390/ cells 9061536

Zhong, W., Xu, M., Li, C., Zhu, B., Cao, X., Li, D., et al. (2019). ORP4L extracts and presents PIP 2 from plasma membrane for PLC 33 catalysis: targeting it eradicates leukemia stem cells. Cell Rep. 26, 2166-2177. doi: 10.1016/j.celrep. 2019.01.082

Conflict of Interest: The authors declare that the research was conducted in the absence of any commercial or financial relationships that could be construed as a potential conflict of interest.

Copyright $\odot 2021$ Ahumada-Castro, Bustos, Silva-Pavez, Puebla-Huerta, Lovy and Cárdenas. This is an open-access article distributed under the terms of the Creative Commons Attribution License (CC BY). The use, distribution or reproduction in other forums is permitted, provided the original author(s) and the copyright owner(s) are credited and that the original publication in this journal is cited, in accordance with accepted academic practice. No use, distribution or reproduction is permitted which does not comply with these terms. 